ISSN 1112-9867

Available online at

http://www.jfas.info

\title{
INVESTIGATING THE EFFECTS OF WATER VAPORIZATION ON THE PRODUCTION OF GAS CONDENSATE RESERVOIRS
}

\author{
S. Zarinabadi ${ }^{*}$, A. Samimi \\ Department of Chemical Engineering, Mahshahr Branch, Islamic Azad University, \\ Mahshahr, Iran
}

Published online: 25 June 2016

\begin{abstract}
Well productivity is an important issue in the development of most low and mediumpermeability gas-condensate reservoirs. However, accurate forecasts of productivity can be difficult because of the need to understand and account for the complex processes that occur in the near-well region. When the well pressure falls below the dew-point, a region of high liquid saturation builds up around the well, impairing the flow of gas and reducing the well productivity. It is essential to take account of this condensate-blockage effect when calculating well productivity. Most of the pressure drop in a gas condensate well occurs close to the well walls. Because of the increase in pressure drop and the increase in flow rate, two additional phenomena get involved in gas flow control: The effect of positive coupling (due to increased capillary number) and the effect of inertia (due to non-Darcy flow). In many gas-condensate wells, the final result of these two parameters is improving well productivity, reducing the impairment caused by condensate blockage. Another phenomenon that can take place in high temperature gas reservoir is water vaporization.
\end{abstract}

Author Correspondence, Email: zarinabadi@yahoo.com

doi: http://dx.doi.org/10.4314/jfas.8vi2s.98 
Pressure drop near well wall causes molar content of water in gas-phase to increase, therefore connate water starts to vaporize near the well walls. This change in connate water saturation near the well wall can influence well productivity by changing saturation of fluids near well walls. The effect of water vaporization on well productivity of gas and gas - condensate reservoirs are investigated by considering a single well one dimensional radial model simulation. The simulations show that water vaporization increases productivity of well by increasing gas saturation and relative permeability near the well walls and improving the mobility of gas; and this effect is stronger in rich gas condensate reservoir than the lean ones.

Keywords: Well, Gas, Pressure Drop, Vapor pressure of water

\section{INTRODUCTION}

The importance of gas condensate reservoirs has increased since the late 30 s, when explorations and deep excavations started to increase. Development and optimal production of these reservoirs needs engineering and operational methods, which makes them different from gas and oil reservoirs. By comparing the reservoirs of dry gas and gas condensate, important parameters which can affect the performance of gas condensate reservoirs can be found. Precise engineering calculations for gas-condensate systems (e.g. wells testing, assessment of exploitable gas, wellhead equipment, etc.) depend on a deep understanding of the phase behavior of the system and the relationship between gas and condensates.

Reduction of the productivity of well is crucial in the development of gas condensate fields, when the pressure drops below the dew point pressure. When the pressure is below the dew point, condensates go out of gas phase and create saturation of condensate near the walls. This, in turn, decreases the rate of productivity of these reservoirs.

This phenomenon happens even in very lean condensate reservoirs. Numerous examples of well productivity reduction can be found in the literature of gas condensate reservoirs. Predicting the performance of condensate gas reservoirs requires modeling of two-phase relative permeability near the well walls, which itself depends on a change in capillary number). Improvement in the mobility of fluid due to high capillary number is the most important seen in the area around the mouth of the well in condensate gas reservoirs. However, 
non-Darcy flows which are mainly created by high velocity in reservoirs tend to decrease fluid mobility. Another important phenomenon which occurs in high- temperature gas condensate reservoirs is water vaporization near well walls. The occurrence of this phenomenon adds to the complexity of simulation in gas condensate reservoirs. This phenomenon which occurs I high temperatures improves productivity too.

this phenomenon also affects the behavior of other fluids near well mouth, although this phenomenon has not been modeled in many simulations done.

Gas condensate reservoirs, flow behavior, and reservoir performance. Flow behavior of gas condensate reservoirs: According to the definition, gas condensate reservoirs are carbohydrate reservoirs the temperature of which is more than the critical temperature and less than the maximum biphasic temperature of the system. Reverse condensation is the most common feature of these reservoirs which occurs in fixed-temperature paths in the reservoirs.

\section{Gas Reservoirs Are Classified as Follows}

Dry gas reservoirs the temperature of which exceeds the maximum biphasic temperature and surface temperature is out of biphasic range. Wet gas reservoirs the temperature of which exceeds the maximum biphasic temperature but surface temperature is in biphasic range. Gas condensate reservoirs the temperature of which lies between critical temperature and maximum biphasic temperature. Phenomena occurring close to the wall of a well in condensate gas reservoirs. The region close to well wall has the biggest effects on the productivity of Gas condensate reservoirs. Analysis has shown that the productivity of the wells highly depends on the distribution of saturated condensates in the region close to the wall of the well. Productivity of gas condensate wells is greatly affected by the balance between physical phenomena that occur due to pressure changes during the life of the reservoir. The formation of a bank of fluids and the effect of non-Darcy flow are among the physical phenomena reducing the productivity of the wells while, increasing capillary number leads to the increase of relative permeability and finally the increase of productivity. Another parameter increasing the productivity of gas condensate reservoirs is water evaporation close to well walls, which occurs in high-temperature gas condensate reservoirs. It is the balance between these parameters which determines the productivity of gas condensate reservoir. 


\subsection{The Effect of Fluid Velocity and Surface Tension Forces}

The region close to the walls can be distinguished by the high pressure gradient and high velocity of fluids, compared to other regions. However, the velocity in the bulk of reservoir is much less than that of the regions near the mouth of the well. In conditions when the temperature and pressure exceed those of the initial fluid reservoir, the reservoir shows behavior close to critical and characteristics of gas and liquid phases will be very close to each other. This means surface tension forces between these two phases are little. In such conditions, it is not only saturation which affects relative permeability of phases, as the features of other fluids highly affect the relative permeability of the two phases, too.

\subsection{Simulating the Effects of Water Vaporization near Well Walls on the Performance of Dry Gas Wells}

In the first section, the parameters affecting the phenomenon of water vaporization in dry gas wells will be investigated through a single well radial model simulation. In the next part, the effect of this phenomenon on the performance of productive wells in dry gas reservoirs will be investigated through a single well radial model simulation in quasi-steady state. The results of the simulations will be presented in each part, separately. The simulations were done using GEM, combined emulation software.

\section{Parameters affecting water vaporization}

Making the model required for simulation

A $1 \times 1 \times 62$ grid dry gas reservoir containing methane and connate water in radial coordinates was selected and smaller grids near the productive well were selected in a way to be able to show the roles of the phenomena near well wall more clearly. The smallest grid is 0.25 feet long and the biggest grid, which is also the outermost, is 600 feet long. On average, each grid has porosity of $10 \%, 30 \mathrm{mg}$ Darcy permeability and water saturation of $20 \%$. Relative permeability has been built based on Corey model and Peng- Robinson equation has been considered as the equation of state. Some points should be considered in simulation: firstly, in equation of state, water should be entered as a parameter; secondly, because the reservoir fluid mainly is composed of a single component, regression of the equation of state is not required. The initial pressure of the dry gas reservoir is considered to be 5000 Psi and 
the Debi of the reservoir is $10 \mathrm{MMSCF}$.

\subsection{The effect of pressure on the amount of water vaporization}

Pressure distribution is shown in a reservoir with 350 Fahrenheit-degree temperature and semi-logarithmic Cartesian coordinates. The figure below shows when the pressure drops due to production, along with the wave of pressure drop, a wave of water vaporization also starts and moves toward the bulk of reservoir. The mole fraction of water in gas phase grows exponentially with pressure drop, resulting in the reduction of water saturation and of course, dryness of the region near well walls.

\subsection{The effect of temperature on the amount water vaporization}

Two different temperatures were selected to investigate the effect of temperature on water vaporization near well walls. These two temperatures were 250 and $350 \mathrm{~F}$, respectively. When the temperature is 250 Fahrenheit degrees, a distance of 7.5 feet to well mouth is dry, while in 350 Fahrenheit degrees, this distance increases to 17.5 feet.

\subsection{The effect of permeability on water vaporization}

Permeability can be considered a crucial factor in distribution of pressure in reservoir. In order to investigate the effect of absolute permeability on water vaporization near well walls, two permeability of 10 and 30 mille Darcy were used in simulation. By controlling the other parameters of reservoir, it was shown that reducing permeability from 30 to 10 increases layer dryness from 17 to 32 feet.

\subsection{The effect of porosity on water vaporization}

The effect of porosity values of 10 and $20 \%$ on the amount of water vaporization near well walls was studied for 500 days after production. When the porosity reduces the amount of empty space also reduces, resulting in more pressure decrease and more water vaporization. With other variables being controlled, porosity change from $20 \%$ to $10 \%$ increases 11 feet dryness of well mouth to 20 feet.

\subsection{The effect of connate water vaporization near well walls on the productivity of high-temperature gas reservoirs}

To evaluate the effect of water vaporization near well walls in high-temperature dry gas reservoirs, a radial, $1 \times 1 \times 62$ grid reservoir containing methane was chosen. Methane gas is 
in equilibrium with the water in the reservoir in the initial conditions and the grids near well mouth are chosen small in order to depict this phenomenon more clearly. The smallest grid is 0.25 feet long and the biggest grid is 1000 feet long. Each grid has average porosity of $10 \%$, $30 \mathrm{mg}$ Darcy permeability, and 20\% connate water. Relative permeability has been built based on Corey model and Peng- Robinson equation has been considered as the equation of state. Some points should be considered in simulation: firstly, in equation of state, water should be entered as a parameter; secondly, because the reservoir fluid mainly is composed of a single component, regression of the equation of state is not required. The initial pressure of the dry gas reservoir is considered to be $5000 \mathrm{Psi}$ and the temperature is $350^{\circ} \mathrm{F}$. there were two conditions in simulation of this reservoir: 1-maximum Debi of production was 30 million standard cubic feet and 2- minimum pressure Draw Down is 1000Psi. The simulation completed in 3,500 days and the effect of connate water vaporization on pressure Draw Down, flow Debi, cumulative production and productivity index was investigated.

Table.1 simulation parameters of well productivity

\begin{tabular}{ll}
\hline Parameter & Amount \\
\hline External radius & $7000 \mathrm{ft}$ \\
The radius of the mouth of the well & $0.5 \mathrm{ft}$ \\
Thickness & $30 \mathrm{ft}$ \\
& $30 \mathrm{md}$ \\
Permeability & $10 \%$ \\
Porosity & $20 \%$ \\
Saturation of connate water & \\
Temperature & $30 \mathrm{MMSCF}$ \\
Volumetric flow rate & $62 \times 1 \times 1$ \\
Simulation grids & Corey \\
Relative permeability & $5000 \mathrm{psi}$ \\
\hline Initial pressure &
\end{tabular}

The effect of connate water vaporization on pressure draws down. When there is Non-Darcy 
flow in the reservoir, the following relationship by Dake exists between Debi and pressure. Different scenarios have been used to investigate the phenomenon of connate water vaporization near well walls in high-temperature dry gas reservoirs. The first scenario was called Base case in which non-Darcy flow was not considered in simulations. The second scenario takes account of non-Darcy flow in simulations. To this end, *NONDARCY1code is used in data file. This code makes it possible to use Geerstma relationship to calculate non-Darcy flow ratio to be used in simulation calculations. In the third scenario, both the non-Darcy flow and the phenomenon of water vaporization are considered. The phenomenon of water vaporization near well walls can be simulated in data file through *H2O_INCLUDED or *OGW_FLASH *ON codes. These cods make it possible to involve water saturation changes in the calculations to see the effects of it on simulation.

When water vaporization occurs near well walls, saturation of connate water will decrease and consequently non-Darcy flow rate (inertia ratio) will decrease, which prevents further reduction of pressure. Therefore, when the phenomenon of water vaporization is considered in simulation, pressure draw down will decrease as a result of reduction in pressure drop.

\subsection{The Effect of Connate Water Vaporization on Debi of Production and Cumulative Production}

In data file, pressure draw down of 1000 Psi was determined and simulator continues production with a fixed Debi until pressure draw down reaches 1000 Psi. Then, Debi is reduced as much as necessary so that pressure draw down is kept at the determined level (1000 Psi). If non-Darcy flow is activated in the simulation, pressure draw down reaches its minimum defined value (1000 Psi) sooner as a result of the extra pressure drop. In conditions when water vaporization is activated, since beta decreases, pressure drop near well walls decreases too and it takes longer for pressure draw down to reach the defined value.

\subsection{The effect of connate water vaporization on productivity index (PI) of gas wells}

The relationship below can be used to calculate PI of gas wells:

$\mathrm{PI}=\mathrm{Q} /\left(\left(\mathrm{P}^{\wedge} 2-\mathrm{P}_{-} \mathrm{wf}^{\wedge} 2\right)\right)$

In gas wells, PI has reverse relationship with pressure draw down and average pressure difference of well $\left(\mathrm{P}^{\wedge} 2-\mathrm{P}_{-} \mathrm{wf}^{\wedge} 2\right)$ 
The greater the pressure difference, the smaller the fraction and the smaller productivity index. Any factor which prevents the reduction of pressure draw down, increases productivity index. When there is non-Darcy flow in reservoir, the pressure difference is bigger than when non-Darcy flow is not considered. This is because the existence of inertia ratio is a factor contributing to the drop of pressure draw down and it increases the gap between average pressure and pressure draw down by decreasing pressure draw down. This factor enlarges denominator of the fraction and results in the decrease of productivity. As it was mentioned before, the phenomenon of water vaporization near well walls results in the formation of a new profile of connate water saturation. When connate water decreases, non-Darcy flow rate (inertia ratio) decreases too and reduced extra pressure drop. Therefore, as it is seen in previous figures, pressure draw down in such conditions is more than the time when only non-Darcy flow is considered. The more the pressure draw down, the less the gap between average pressure and pressure draw down, the smaller the denominator, and the higher the productivity. It can clearly be shown that the phenomenon of water vaporization can increase productivity index by reducing the negative effect of non-Darcy flow.

\section{CONCLUSION AND SUGGESTIONS}

The present research study aimed at investigating the effect of the phenomena near well walls, especially connate water vaporization, firstly on high-temperature gas reservoirs, then on lean gas condensate reservoirs and finally on rich gas condensate reservoirs. The findings are as follow:

\subsection{Findings}

The phenomenon of water vaporization in gas reservoirs and gas condensate reservoirs occurs at high temperature and depends on pressure and temperature. Temperature rise and pressure drop accelerate this phenomenon.

Porosity decrease and permeability reduction lead to more pressure drop, resulting in more water vaporization.

Reduction of connate water saturation reduces the inertia ratio, which itself leads to the increase in pressure drop and the increase in the rate of productivity. 
The phenomenon of water vaporization in condensate gas reservoirs occurring near the mouth of wells increases gas phase relative permeability, increases gas phase saturation and improves productivity of well.

This study showed that the phenomenon of water vaporization should be considered in simulation of gas condensate reservoirs and it is only GEM software from CMG package which is able to simulate this phenomenon.

\subsection{Suggestions}

More complex reservoir models and a higher number of wells can be used in further research studies.

For better investigation, a larger number of samples of rich and lean fluids can be investigated.

With access to true information about production, more reliable and accurate results can be achieved.

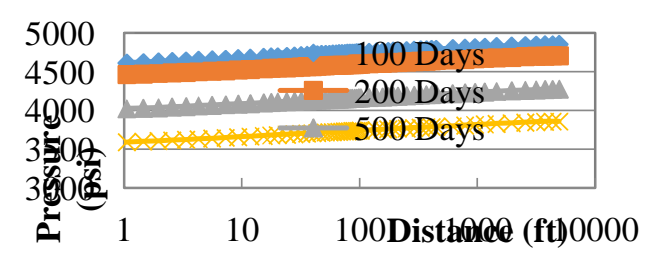

Fig.1.The distribution of pressure of reservoir with Cartesian coordinates

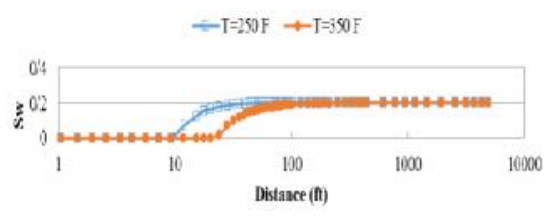

Fig.2. Pressure distribution in semi-logarithmic coordinates

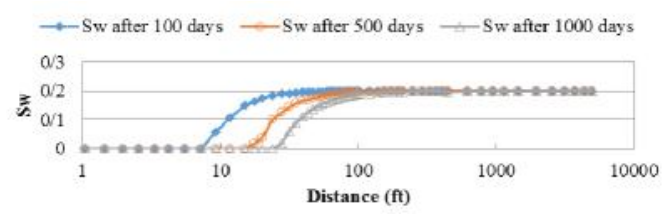

Fig.3. Water saturation distribution in 350 Fahrenheit degrees, 100, 500 and 1000days after production 


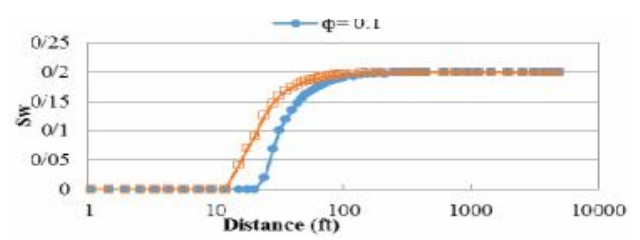

Fig.4.The effect of temperature on connate water vaporization

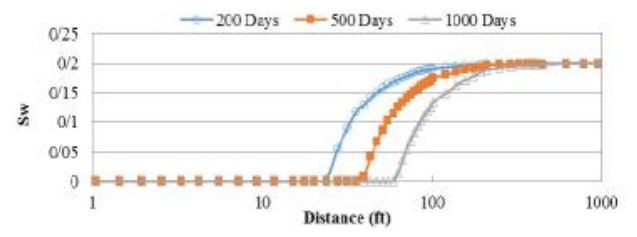

Fig.4.The profile of connate water saturation 200, 500 and 1000days after the start of production

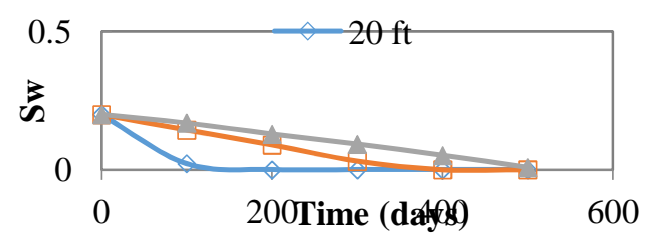

Fig.5.The changes in the saturation of connate water at varying times

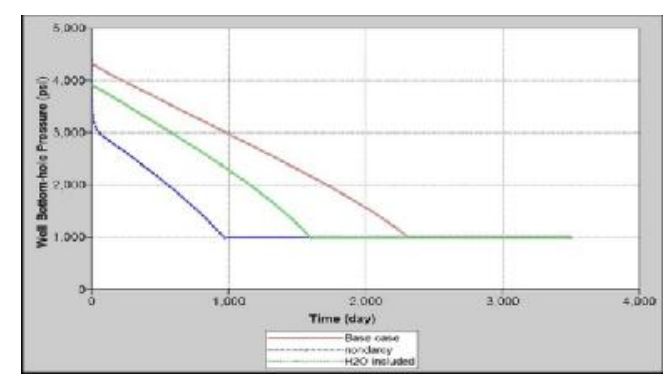

Fig.6.The comparison of pressure drawdown in 3 different scenarios: without considering non-Darcy flow and connate water vaporization, considering non-Darcy flow, and considering both non-Darcy flow and connate water vaporization

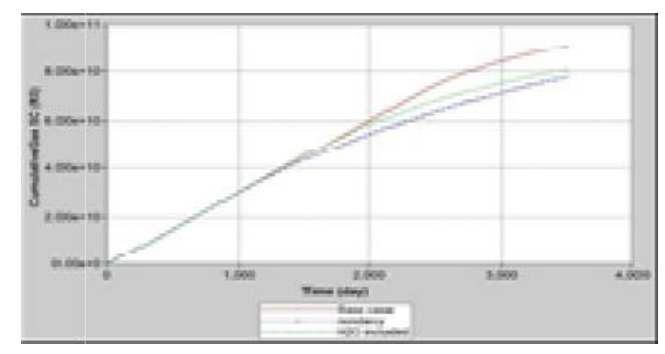

Fig.7.The comparison of cumulative production in in 3 different scenarios: without considering non-Darcy flow and connate water vaporization, considering non-Darcy flow, and considering both non-Darcy flow and connate water vaporization 


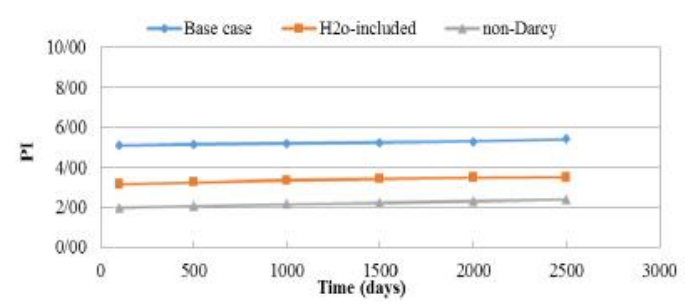

Fig.8.The comparison of productivity in 3 different scenarios: without considering non-Darcy flow and connate water vaporization, considering non-Darcy flow, and considering both non-Darcy flow and connate water vaporization

\section{REFFERENCES}

[1] Adams, D. B. (1998) "Regional Water Issues, Newsletter of the U.S. National Assessment of thePotential Consequences of Climate Variability and Change," Acclimations, 11-12 [2] American Society of Civil Engineers and the Working Group of UNESCO/IHP IV Project M-4.3, Reston, VA.

[3] Anderson, J. (2003) “The Environmental Benefits of Water Recycling and Reuse," Water Sci. Technol: Water Supply, 3, 4, 1-10.

[4] Asano, T. (2002) "Water from (Waste) Water-the Dependable Water Resource," Water Sci. Technol., 45, 8, 24-33.

[5] ASCE (1998) Sustainability Criteria for Water Resources Systems, prepared by the Task Committee on Sustainability Criteria, Water Resources Planning and Management Division, [6] Baron, J. S., N. L. Poff, P. L. Angermeier, C. N. Dahm, P. H. Gleick, N. G. Hairston, R. B. Jackson, C. A. Johnston, B. D. Richter, and A. D. Steinman (2002) "Meeting Ecological and Social Needs for Freshwater,” Ecol. Appl., 12, 5, 1247-1260.

[7] Bouwer, H. (2000) "Integrated Water Management: Emerging Issues and Challenges," Agric. Water Mgmt., 217-228.

[8] Braden, J. B., and E. C. van Ierland (1999) "Balancing: the Economic Approach to Sustainable Water Management," Water Sci. Technol., 39, 5, 17-23.

[9] Cosgrove, W. J., and F. R. Rijsberman (2000) World Water Vision: Making Water everybody's Business, Earthscan Publications, London, UK. 
[10] Falkenmark, M., and G. Lindh (1993) "Water and Economic Development," in P. H. Gleick (ed.), Water in Crisis: A Guide to the World's Fresh Water Resources, Pacific Institute for Studies in Development, Environment, and Security, Stockholm Environment Institute, Oxford University Press, New York.

[11] Falkenmark, M., and M. Widstrand (1992) "Population and Water Resources: A Delicate Balance," Population Bulletin, Population Reference Bureau, Washington, D.C., 47, 3, 2-35,

[12] Foster, K. R., P. Vecchia, and M. H. Repacholi (2000) "Science and the Precautionary Principle," Science, 288, 5468, 979-981.

[13] Gleick, P. H. (2000) "The Changing Water Paradigm: A Look at Twenty-First Century Water Resources Development," Water Inter., 25, 1, 127-138.

[14] Harremoës, P. (2002) "Water Ethics: a Substitute for Over-Regulation of a Scarce Resource. Water Scarcity for the 21st Century-Building Bridges through Dialogue," Water Sci. Technol, 8, 113-124.

[15] Harremoës, P., D. Gee, M. MacGarvin, A. Stirling, J. Keys, B. Wynne, and S. G. Vaz, (eds.) (2001) "Late Lessons from Early Warnings: the Precautionary Principle 1896-2000," Environmental Issue Report, No. 22, European Environment Agency, Copenhagen, Denmark. [16] Hermanowicz, S. W. (2005) "Sustainability in Water Resources Management: Changes in Meaning and Perception," University of California Water Resources Center Archives. http://repositories.cdlib.org/wrca/wp/swr_v3

[17] Hermanowicz, S. W., and T. Asano (1999) “Abel Wolman's “The Metabolism of Cities" Revisited: A Case for Water Recycling and Reuse,” Water Sci. Technol., 40, 4-5, 29-36.

[18] Huesemann, M. W. (2003) “The Limits of Technological Solutions to Sustainable Development," Clean Tech. Environ. Pollut., 5, 1, 21-34.

[19] IWMI (2000) "World Water Supply and Demand: 1990 to 2025," International Water Management Institute, Colombo, Sri Lanka.

[20] Krayer von Krauss, M., M. B. A. van Asselt, M. Henze, J. Ravetz, and M. B. Beck (2005) “Uncertainty and Precaution in Environmental Management,” Water Sci. Technol., 52, 6, 1-9. 
[21] Mackun, P. J., and S. R. Wilson (2000) Population Trends in Metropolitan Areas and Central Cities: 1990 to 1998, Current Population Reports, P25-1133, U.S. Department of Commerce, U.S. Census Bureau, Washington, DC.

[22] Maddaus, W. O. (2001) Water Resources Planning: Manual of Water Supply Practices, AWWA Manual M50, American Water Works Association, Denver, CO.

[23] Mantovani, P., T. Asano, A. Chang, and D. A. Okun (2001) Managing Practices for Nonpotable Water Reuse, Project 97-IRM-6, Water Environment Research Foundation, Alexandria, VA.

[24] Mayer, P. W., W. B. DeOreo, E. M. Opitz, J. C. Kiefer, W. Y. Davis, B. Dziegielewski, and J. O. Nelson, (1999) Residential End Uses of Water, American Water Works Research Foundation, Denver, CO.

[25] Nations Population Division, Department of Economic and Social Affairs, United Nations, New York.

[26] Postel, S. L. (2000) "Entering an Era of Water Scarcity: the Challenges Ahead," Ecol. Appl., 10, 4, 941-948.

\section{How to cite this article:}

Zarinabadi S, Samimi A, Nasrollahzadeh B. Investigating the effects of water vaporization on the production of gas condensate reservoirs. J. Fundam. Appl. Sci., 2016, 8(2S), 1160-1172. 